\title{
Thorny problem as Australia's coastline faces invasion
}

\section{Sydney}

REPORTS that Australian and Japanese companies are having second thoughts about building tourist facilities on the Great Barrier Reef have lent new urgency to the search for ways to control the Crown-of-Thorns starfish (Acanthaster planci).

The starfish continues to spread south, towards potential recreational sites, destroying large sections of reef. Yet Australian scientists are increasingly divided over the causes of the outbreak and what can be done to control it.

The first outbreak was recorded around Green Island, in the central third of the reef, in 1964. In 1979, during another outbreak at the same island, 3,000,000 star-

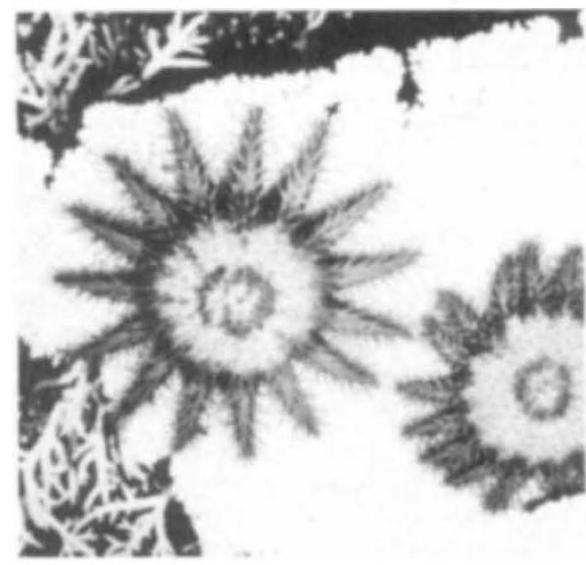

Rampant starfish.

fish were counted (the normal population density is about 6 starfish per square kilometre). By 1981, 90 per cent of the coral had gone and the starfish had moved to reefs further south.

Dr Bob Endine, associate professor at the University of Queensland, believes the starfish infestations are due to human intervention. "It is an ecocatastrophe of the first order" explained by over-collection of predators such as the Giant Triton. Reefs where predators have not been removed have remained "starfish-free", according to Endine.

Endine believes the only solution is to maintain a continual clearing programme and to prevent overfishing. He wants the government to ban the taking of molluses and fish and wants crown-of-thorns starfish to be collected from the periphery of infested areas to prevent them from spreading. "A vigil must be kept", he says.

But many others are not convinced. Dr Peter Moran and Dr Roger Bradbury from the Australian Institute of Marine Science (AIMS), who are working on the still-obscure lifecycle of the starfish, believe the causes of the infestation will require better understanding of the reef and the relationship of the starfish to it.
As evidence that starfish control by clearing is ineffective, they cite a largescale control programme in Japan where, over the past 20 years, approximately 13 million starfish have been removed from reefs in a designated region at a cost of A \$6 million. Starfish nevertheless remain, continuing widespread coral devastation.

Endine counters that control measures have previously been conducted in ways unlikely to succeed. He notes that the Japanese 'clearance' depended on a bounty system, meaning that only large starfish were picked up. In an Australian effort, "the army collected on only a section of a reef for two weeks", after which the starfish moved back.

AIMS and the Great Barrier Reef Park Marine Authority get $\mathrm{A} \$ 700,000$ a year from the government over a four-year period, but senior project manager for research and maintenance of the Great Barrier Reef Marine Park Authority, Dr Leon Zann, is lobbying to have the funds

spread over a longer period of time.

"This is not a four-year problem, but will need decades of dedicated research." Zann also believes that the cause is yet to be known, saying that there is a need to know more about the life cycle of the pest and about the reef, which is why attention has turned to Fiji, Tonga and other Pacific regions where outbreaks have occurred. He notes that geological data show that starfish have been abundant in the past and that "this is not a modern phenomenon"

A major concern is the tourist dollar With the coral as the drawcard on the reef, Japanese and Australian developers may decide not to invest in resort development because of fear of infestations.

The slow southward movement of the crown-of-thorns starfish is probably due to currents carrying larvae and the movement of adults in search of food. Endine believes that the fear for the tourist dollar is well founded. While moored submersible islands, floating hotels and man-made islands have been developed on the reef at more southerly sites to avoid the infestation, "the starfish are moving south too".

Tania Ewing

\section{OECD report attacks national policies}

Paris

THE Organisation for Economic Co-operation and Development (OECD), in a report* just published, says that member states are not paying enough attention to the potential uses of biotechnology in the control of environmental pollution. The report suggests that widespread public hostility towards genetic engineering could "cause considerable delays in the diffusion of many harmless and beneficial products and processes".

Awareness of this hostility, rather than empirical research, has, says the report, encouraged environment ministries to maintain a defensive position against hypothetical risks of the release of genetically altered micro-organisms, instead of exploiting the many ways in which biotechnology might help them to monitor and clean-up the environment. Positive examples already being exploited in the United States and in France - include the use of biosensors as pollution monitoring devices and the development of improved waste treatment systems.

The lack of research to assess the real risks involved in the environmental release of genetically engineered micro-organisms is, claims the report, "rather disturbing". In the absence of criteria and methodologies for risk assessment, companies are often unwilling to embark on new avenues of research. This deadlock was found to be maintained by "lax regulations" in many member states which prefer to impose fines for waste emission, rather than to set up efficient industrial treatment programmes. Also to blame is the lack of importance ascribed to risk assessment, which fails to attract sufficiently talented researchers.

More generally, traditional separation of biological and engineering faculties in universities, while gradually being changed serves as an obstacle to the interdisciplinary training of researchers needed to respond to a growing manpower shortage in industrial biotechnology. In France this common problem is compounded by the physical separation of the Grandes Ecoles, which train the most qualified engineering students, from the universities, where most research scientists are educated.

To improve private sector investment in what remains a high-risk, long-term research area, the report recommends international pooling of scientific information and the development of databases, regulatory mechanisms to ensure intellectural property and the freedom to publish findings (often an obstacle to university collaboration with industry), as well as better diffusion of information to maintain public confidence.

Given that more patent applications for commercially useful biotechnology inventions arise from basic research than from industrial, applied research, the report stresses that the biotechnology boom should not tempt governments to neglect the role of pure science. Peter Coles

*Biotechnology and the changing role of govrnment (OECD, Paing, 1988) 